\title{
Espaço cibernético, cibercultura e pesquisa acadêmica
}

Cyberspace, cyberculture and academic research

Marcos Silva*

\section{Resumo}

O texto relata os resultados de uma pesquisa sobre cibercultura e as possibilidades de sua utilização pedagógica. Além disso, descreve os esforços de construção de um instrumento metodológico de pesquisa acadêmica utilizando o espaço cibernético como principal fonte de informações.

Palavras-chave: cibercultura; pesquisa acadêmica; representação docente.

\section{Abstract}

The text is the report of the results of a research about cyberculture and the possibilities of its pedagogic use. Besides, it describes the efforts of construction of a methodological instrument of academic research using the cybernetic space as main source of information.

Keywords: cyberculture; academic research; educational representation.

O intuito deste artigo é descrever o desenvolvimento de uma pesquisa que teve como um dos objetos de estudo as principais manifestações da mais nova fronteira cultural da humanidade, a cibercultura. Acrescenta-se a esse objetivo a exposição do teste, aplicado durante a pesquisa, de um instrumento que se destinava a sugerir uma metodologia de utilização do espaço cibernético como fonte de pesquisa acadêmica.

Com base no Projeto de Pesquisa intitulado "A Integração do Ciberespaço na Práxis dos Professores de Humanidades", admitiu-se como uma das hipóteses de trabalho a necessidade de os professores de ciências humanas incorporarem uma nova dinâmica pedagógica tendo como suporte o espaço cibernético. Dentre os recursos indicados na pesquisa para a consecução desse objetivo destaca-se, pelo seu caráter original, a apropriação pedagógica da

\footnotetext{
* Departamento de História, Universidade Federal de Sergipe (UFS). Cidade Universitária Prof. José Aloízio de Campos. Av. Marechal Rondon, s/n, Jardim Rosa Elze. 49100-000 São Cristóvão -SE - Brasil.silva.marcos@uol.com.br
} 
cibercultura e o exame das possibilidades iniciais de introdução de algumas dessas manifestações ${ }^{1}$ no currículo escolar.

Com o fim de executar uma pesquisa exploratória no ciberespaço em busca de websites dedicados às principais manifestações da cibercultura, foram incorporados/as à equipe do projeto três bolsistas de IC Júnior (Iniciação Científica Júnior) que, após a realização de leituras básicas de fundamentação teórica, foram apresentados/as ao desafio da construção de um instrumento que servisse de roteiro para guia-los nas incursões pela internet.

Na realidade, a coordenação da pesquisa tomou como ponto de partida a necessidade do estabelecimento de critérios para a análise de websites, utilizados como fonte de informação de pesquisa acadêmica. Às voltas com problemas de validação e normalização de documentos online, ${ }^{2}$ de interface gráfica e de filtragem de conteúdos, e com um número viável de websites para análise, percebeu-se a necessidade de construção de um instrumento capaz de metodologizar a pesquisa e que pudesse servir de subsídio para pesquisas acadêmicas que fizessem uso do espaço cibernético como fonte de pesquisa.

Na realidade, é bom esclarecer, não se trata meramente da possibilidade de acesso a documentos, artigos, livros, ensaios, dissertações e teses que são disponibilizados online, algo que diz respeito à digitalização da cultura escrita. Para esse tipo de pesquisa já se podia contar com ferramentas como o Google Scholar que, na descrição do próprio website,

Fornece uma maneira simples de pesquisar literatura acadêmica de forma abrangente. Você pode pesquisar várias disciplinas e fontes em um só lugar: artigos revisados por especialistas (peer-rewiewed), teses, livros, resumos e artigos de editoras acadêmicas, organizações profissionais, bibliotecas de pré-publicações, universidades e outras entidades acadêmicas. O Google Acadêmico ajuda a identificar as pesquisas mais relevantes do mundo acadêmico. ${ }^{3}$

A nova perspectiva é outra, e implica partir do pressuposto de que o espaço cibernético é um fenômeno tão significativo para o homem pós-moderno que as suas manifestações culturais peculiares constituem-se em um novo e importante objeto de investigação acadêmica. Assim, convém estabelecer princípios para nortear pesquisas exploratórias que tomem os conteúdos produzidos e veiculados na internet como corpus documental principal. 
Lucia Santaella explica que esse novo campo de investigação se deve à circunstância de que "o computador colonizou a produção cultural. Uma máquina que estava destinada a mastigar números, começou a mastigar tudo: da linguagem impressa à música, da fotografia ao cinema. Isso fez da cibernética a alquimia do nosso tempo e do computador seu solvente universal". ${ }^{4}$

Deve-se, porém, acrescentar um breve adendo a essa constatação de Lucia Santaella. Assmann complementa bem ao afirmar:

Fica evidente que deixou de fazer sentido falar do computador como se fosse uma referência totalizável em si. Entenda-se bem: o computador isolado já se tornou um objeto obsoleto. Hoje o computador só faz sentido como nó de acesso a essa vasta redificação planetária. E como tal passou a ser entendido pela quase totalidade de seus usuários. Essa imersão nas redes digitais passou a ser uma experiência concreta até mesmo das crianças, que têm acesso a um computador ligado à rede mundial de computadores. O computador isolado deixou praticamente de existir e, com sua desaparição, desapareceram muitos aspectos da anterior experiência do aprender. ${ }^{5}$

\section{INSTRUMENTO PARA SISTEMATIZAÇÃO DE PESQUISAS NA INTERNET}

Como maneira de encaminhar a construção do formulário para a sistematização da procura de documentos/websites foram propostas algumas leituras à equipe de trabalho, como maneira de possibilitar a participação de todos na elaboração da ferramenta de pesquisa. Dentre as leituras, merecem destaque aquelas realizadas com o objetivo de compreender a lógica de funcionamento do principal mecanismo de busca em operação na atualidade, o Google. ${ }^{6}$

Uma primeira dificuldade foi a determinação de um critério que justificasse, diante da imensa quantidade de websites localizados pelo mecanismo de busca quando de uma pesquisa, a análise de determinado número de páginas. Porém, a própria lógica de funcionamento do mais eficiente mecanismo de busca em operação, o Google, ajudou a encaminhar a solução desse problema, uma vez que os websites são relacionados de acordo com um critério lógico de importância dentro do ciberespaço. ${ }^{7} \mathrm{Na}$ explicação do próprio Google, o mecanismo de busca trabalha assim: 
O Google funciona através de uma combinação complexa de hardware e software tecnologicamente avançados ... O PageRank (algoritmo de pesquisa do Google, ou seja, um sistema de classificação e ordenamento de páginas web) assenta na natureza excepcionalmente democrática da web, ao utilizar a sua vasta estrutura de links como uma medida do valor de uma página individual. Essencialmente, o Google interpreta um link da página A para a página $\mathrm{B}$ como um voto da página $\mathrm{A}$ em direção à página $\mathrm{B}$. No entanto, o Google analisa mais do que o simples volume dos votos ou os links recebidos por uma página; analisa, também, a página que lança o voto. Os votos dados pelas páginas que são, por si próprias, 'importantes', têm maior peso e ajudam a tornar outras páginas 'importantes.'

Desse modo, admitindo-se que os websites que resultam de uma pesquisa já aparecem obedecendo a uma ordem lógica de importância, convencionou-se analisar apenas $10 \%$ dos primeiros resultados apresentados como resposta a uma pesquisa efetuada.

Em seguida, procedeu-se à identificação das principais manifestações da cibercultura que, além de consistirem na estrutura lógica da investigação em operação, determinariam os termos principais a serem utilizados nas buscas na internet. Foram selecionadas as seguintes expressões culturais: blogosfera, ciberarte (web arte), poesia digital, ciberjornalismo, comunidades virtuais, cibercidadania, ciberpsicologia e cibergeografia.

Depois dessa etapa, chamada no formulário de coleta de dados de 'Fase Global', iniciou-se a testagem do instrumento mediante duas manifestações da cibercultura, escolhidas aleatoriamente: 'poesia digital' e 'comunidades virtuais'. Para cada uma dessas expressões da cibercultura foram determinadas, como fruto de uma pesquisa exploratória inicial, palavras-chave que, distinguidas como termos de maior incidência no assunto pesquisado e, enquanto pormenorização, com um número total de resultados no Google bem menor, viabilizavam uma análise de conteúdo dos documentos/websites encontrados.

$\mathrm{Na}$ fase que se segue, utilizando as palavras-chave específicas, o modelo busca determinar questões ligadas à autoria do documento/website, a confiabilidade das informações prestadas (validação), os requisitos de interface, pequena sinopse do assunto e uma avaliação da possibilidade de utilização docente do conteúdo do website (ver Anexo).

Como os bolsistas de IC Jr. enfrentariam dificuldades se fossem utilizadas outras línguas além do português, definiu-se que as pesquisas ficariam restritas 
ao idioma pátrio. À medida que a pesquisa ia se desenvolvendo, os dados coletados eram enviados para um disco virtual, sendo armazenados para posterior análise e utilização.

\section{ENTENDENDO AS PRINCIPAIS EXPRESSÕES DA CIBERCULTURA}

A consideração da cibercultura como o mais recente e avançado espaço de produção cultural da humanidade se deve ao fato de que a imagem que outrora se tinha da televisão como 'lareira', ou ponto em torno do qual se reunia a família, está sendo substituída, segundo Galimberti e Gatti, ${ }^{9}$ pela imagem do PC como 'novo tear', indicando que a relação dos indivíduos e da família com a nova media não é mais passiva e de mão única (emissor-receptor), mas enseja a produção de informações pelos sujeitos pós-modernos. Essa perspectiva pode ser mais bem compreendida na explicação de Santaella (2003, p.176):

Se é verdade que cada período da história da arte no Ocidente é marcado pelos meios que lhe são próprios, os meios do nosso tempo, neste início do terceiro milênio, estão nas tecnologias digitais, nas memórias eletrônicas, nas hibridizações dos ecossistemas com os tecnossistemas e nas absorções inextricáveis das pesquisas científicas pela criação artística, tudo isso abrindo ao artista horizontes inéditos para a exploração de novos territórios da sensorialidade e sensibilidade.

O 'novo tear', a nova paleta, suporte privilegiado e mídia polivalente, é a telemática. No entanto, esta, ao invés de se constituir como apenas mais um mass media, por suas características singulares está se transformando em um personal media. Em função disso, Turkle ${ }^{10}$ considera que o computador, como 'máquina intimista', tem efeitos subjetivos que tendem a alterar a relação da pessoa com os outros, com a sexualidade, com a política, com a identidade e, deve-se acrescentar, como corolário, com a produção cultural.

Assim, nota-se a importância desse levantamento sobre as produções e manifestações culturais surgidas em função do novo sensorium de base digital. Essa percepção se fortalece na medida em que o advento desse novo meio de comunicação está alterando até a compreensão das categorias tradicionais de explicação da realidade utilizadas por algumas ciências, como é o caso da Sociologia. 


\section{Comunidades virtuais}

Atribui-se a expressão 'comunidade virtual' ao escritor norte-americano Howard Rheingold, que a teria cunhado em 1993, com o lançamento do livro A comunidade virtual (publicado em português pela Gradiva, Portugal). Uma procura no Google por esse termo resulta em algumas centenas de milhares de páginas, mostrando que esse é um dos aspectos mais considerados da nova cultura.

A concepção que Rheingold ${ }^{11}$ passa de comunidade virtual é simples: um novo tipo de cultura, uma teia de relações pessoais mediadas por computador ou agregados sociais que emergem no ciberespaço, que respondem a uma necessidade das pessoas por vivência comunitária, cujas finalidades e/ou possibilidades são as mais diversas possíveis, desde psicoterapia, passando por jogos, chegando a atividades científicas e artísticas, formando um ecossistema de subculturas, com potencial para mudar a relação das pessoas com o mundo real.

No dizer de Castells, "o novo padrão de sociabilidade em nossas sociedades é caracterizado pelo individualismo em rede". ${ }^{12} \mathrm{Ou}$ seja, a própria noção de comunidade está mudando, deixando-se de enfatizar os aspectos espaciais e culturais para ressaltar o seu papel de suporte a indivíduos e famílias. Isso significa que o sentimento de pertença agora se dá com base em interesses compartilhados. Wellman e Gulia ${ }^{13}$ apontam alguns exemplos de como esses novos laços se constroem por meio da internet. Pode ser a partir de informações sobre tratamentos, em função da consulta a médicos especialistas, pela participação em grupos de apoio emocional para pessoas que se recuperam de vícios em álcool e drogas, pelo desejo de obtenção de companhia e conselhos, a partir do teletrabalho etc.

$\mathrm{Na}$ verdade, o que se afigura é a possibilidade concreta de uma glocalização (o global com suporte no local, que está sendo chamado de glocal). Isso porque a partir da infraestrutura técnica proporcionada pela telemática "não é que o mundo tenha se tornado uma aldeia global, como McLuhan disse originalmente, a aldeia particular de cada um pode agora abranger todo o globo", no dizer de Wellman e Gulia (2005).

Dessa forma, percebe-se como as redes sociais amparadas por computador transformaram-se em elemento fundamental de laço social, a ponto de 
Castells (2003) afirmar que as relações de família estão ultimamente sendo ajudadas pelo uso do e-mail.

\section{Cidades digitais}

Com o surgimento do novo meio de comunicação propiciado pela interconexão planetária dos computadores, o ciberespaço, afigura-se também a configuração de, no mínimo, um novo espaço antropológico, espaço de significação ou de proximidade, chamado por Lévy de 'espaço do saber'. ${ }^{14}$

Esse novo sistema de agregação social precisaria, à semelhança do espaço tradicional, desempenhar as mesmas funções de proteção, compartilhamento simbólico e centro de atividades comerciais, administrativas, científicas e beneficentes.

Essa é a pretensão do novo surto urbanístico da humanidade. Desta vez, constituído não de cidades-Estado, mas de cidades virtuais enquanto "novo ambiente tecnológico de mobilização social” (Castells, 2003, p.120). Nesse fenômeno urbano destacam-se as cidades digitais de Amsterdã ${ }^{15}$ Bolonha $^{16} \mathrm{e}$ Aveiro. ${ }^{17}$

Na definição de Zancheti, ${ }^{18}$ uma cidade digital é "um sistema de pessoas e instituições conectadas por uma infraestrutura de comunicação digital (a internet) que tem como referência uma cidade real". Os objetivos dessa cidade vão desde a instauração de uma utópica democracia eletrônica a ser desfrutada pelos netizens, cidadãos da internet, à formação de redes comunitárias, ou seja, integração social; manifestações culturais, notadamente aquelas que caracterizam a nova fronteira cultural da humanidade, a cibercultura; banco de dados sobre a comunidade originária; incubação de negócios; possibilidade de atuação do governo eletrônico, ${ }^{19} \mathrm{o}$ chamado $e$-gov, e divulgação turística, dentre outros.

\section{Poesia digital}

A poesia digital é a poesia

que circula nos computadores (discos rígido e flexível), nos CD-ROMs e nos sites da internet. Essa poesia pode ser chamada de poesia experimental, nova poesia visual, poesia digital, poesia internética ou nova poesia das mídias e, de certa 
forma, ela se constitui num gênero, o gênero da poesia digital, como um dos muitos gêneros de poesia existentes (poesia verbal, visual, sonora etc.). ${ }^{20}$

Com base no levantamento realizado destacou-se a produção de Eduardo $\mathrm{Kac}^{21}$ e a pesquisa de Sergio Caparelli, ${ }^{22}$ da Universidade Federal do Rio Grande do Sul (UFRGS). Uma pesquisa mais detida será suficiente para revelar obras interessantes do novo gênero de poesia. ${ }^{23}$

\section{Webart}

São os trabalhos de arte que foram especialmente desenvolvidos para a internet e que por isso utilizam as possibilidades e características desse meio, como hipertextualidade, interatividade, imaterialidade e reprodutibilidade incalculável. Ou seja, nessa nova expressão cultural ocorre a digitalização dos instrumentos da produção artística.

Algumas manifestações da cibercultura de evidente e imediata aplicação pedagógica são o ciberjornalismo, que já se transformou até em disciplina acadêmica de cursos superiores, e a blogosfera, um campo de expressão pessoal em franca expansão que tem influenciado bastante até a esfera política.

Para uma aplicação pedagógica dos weblogs, importantes sugestões podem ser encontradas no Aulablog, ${ }^{24}$ um projeto desenvolvido por professores espanhóis com sugestões para o uso educacional de blogs, com artigos, experiências e links interessantes.

A questão principal não deixa de ser: "Como se poderia incluir a cibercultura no currículo dos Cursos Superiores de Ciências Humanas?”. As sugestões abrangem desde a proposição de disciplinas específicas sobre cibercultura no currículo até a correspondência com autores de outras universidades (troca de experiências), a utilização de atividades extraclasse e, especificamente no caso do curso de Geografia, a utilização das cidades digitais como modelo para análise e planejamento dos problemas urbanos.

Esta última representa uma excelente sugestão. Porém, a manifestação da cibercultura que desperta especial interesse para o campo da educação é a das comunidades virtuais. Segundo Lévy, "comunidade virtual é um grupo de pessoas se correspondendo mutuamente por meio de computadores interconectados". ${ }^{25}$ Para Castells (2003), as características fundamentais das comunidades virtuais são: o valor da comunicação livre, horizontal, e a formação autônoma 
das redes, sobre o princípio de que qualquer um é livre para divulgar sua mensagem.

Com base nessa classificação e na percepção de que a cultura das comunidades virtuais tem um potencial pedagógico ainda por ser explorado, algumas categorias importantes vêm à tona. Destacam-se os conceitos de 'comunidades aprendentes', 'inteligência coletiva' e 'ecologia cognitiva'.

A ideia básica que se pode apreender da articulação desses conceitos é que as 'comunidades virtuais', enquanto coletivos interconectados para fins pedagógicos, podem aspirar a se tornarem 'comunidades aprendentes' que desenvolvam uma 'inteligência coletiva' a partir do compartilhamento de uma rica 'ecologia cognitiva'.

Na definição de Lévy (2000, p.28), inteligência coletiva “é uma inteligência distribuída por toda parte, incessantemente valorizada, coordenada em tempo real, que resulta em uma mobilização efetiva das competências". O objetivo da inteligência coletiva seria, então, o 'enriquecimento mútuo' das pessoas que partilham a mesma comunidade virtual aprendente.

Para conceituar 'ecologia cognitiva', Lévy argumenta:

Quem pensa? É o sujeito nu e monádico, face ao objeto? São grupos intersubjetivos? Ou ainda as estruturas, as línguas, as epistemes ou os inconscientes sociais que pensam em nós? Ao desenvolver o conceito de ecologia cognitiva, irei defender a ideia de um coletivo pensante homens-coisas, coletivo dinâmico povoado por singularidades atuantes e subjetividades mutantes... ${ }^{26}$

Assim, na perspectiva de Lévy (1993, p.144), uma ecologia cognitiva é formada não apenas por seres humanos, mas também por máquinas, ferramentas, estradas, carros, cidades, enfim, "todos os elementos do universo físico que as ações humanas implicam”. Como fica o professor diante do desafio de propiciar 'ecologias cognitivas' que favoreçam o aprendizado? Lévy responde:

A principal função do professor não pode mais ser uma difusão dos conhecimentos, que agora é feita de forma mais eficaz por outros meios. Sua competência deve deslocar-se no sentido de incentivar a aprendizagem e o pensamento. $\mathrm{O}$ professor torna-se um animador da inteligência coletiva dos grupos que estão a seu encargo. Sua atividade será centrada no acompanhamento e na gestão das 
aprendizagens: o incitamento à troca dos saberes, a mediação relacional e simbólica, a pilotagem personalizada dos percursos de aprendizagem etc. $(1999$, p.171)

O desafio é aproximar as contribuições da pedagogia com as da técnica, aqui representada pelos recursos do ciberespaço, o conteúdo das humanidades, sem olvidar a produção da cibercultura, no intuito de sugerir um processo de formação regular e continuada dos professores de Ciências Humanas que lhes propicie uma nova dinâmica didática.

\section{CONSIDERAÇÕES FINAIS}

Os dados coletados na pesquisa exploratória através da internet em documentos/websites revelam que a cibercultura é um vasto campo aberto para a realização de pesquisas acadêmicas, não só pelo surgimento de novos objetos de pesquisa, mas também porque o ciberespaço permite a adoção de novos procedimentos metodológicos. Além disso, o ciberespaço e a sua cultura correlata também constituem um vasto campo inexplorado, especialmente do ponto de vista educacional.

Ora, essas considerações permitem concluir este breve relatório de pesquisa levantando a tímida hipótese de que as novas possibilidades acadêmicas, as dificuldades sentidas para a sua incorporação pedagógica e até mesmo as hesitações constatadas em relação à cibercultura deixam entrever que esses são fenômenos que se associam a um autêntico movimento de vanguarda. Assim, defendendo a cibercultura como um fenômeno que está guiando a cultura dos dias atuais, sinalizamos para a importância do prosseguimento dos estudos aqui esboçados. 
ANEXO

A INTEGRAÇÃO DO CIBERESPAÇO NA PRÁXIS DOS PROFESSORES DE HUMANIDADES FORMULÁRIO DE AVALIAÇÃO DE WEBSITES / TEMA DA PESQUISA: CIBERCULTURA

\begin{tabular}{|c|c|c|c|c|c|}
\hline \multirow{3}{*}{ 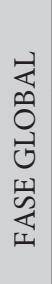 } & \multicolumn{2}{|c|}{ 1. Manifestação da Cibercultura } & \multicolumn{2}{|c|}{ 2. Ferramenta de Busca } & 3. Data de Acesso \\
\hline & \multicolumn{2}{|l|}{ 4. Idioma } & \multicolumn{2}{|c|}{$\begin{array}{l}\text { 5. Resultados }(\Sigma) \\
\text { (Número Total de chamadas) }\end{array}$} & 6. \% de Visitação do $\Sigma$ \\
\hline & $\begin{array}{l}\text { 7. № de Sites } \\
\text { Analisados }\end{array}$ & \multicolumn{4}{|c|}{ 8. Palavras-Chave definidas: } \\
\hline \multirow{19}{*}{ 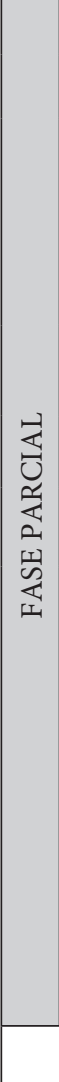 } & \multicolumn{5}{|l|}{ 9. Palavra-Chave Utilizada } \\
\hline & \multicolumn{5}{|l|}{ 10. URL } \\
\hline & \multicolumn{5}{|l|}{$\begin{array}{l}\text { 11. Autor(es) } \\
\text { (Responsável) }\end{array}$} \\
\hline & \multicolumn{5}{|l|}{$\begin{array}{l}\square \text { Pessoal } \\
\square \text { Institucional }\end{array}$} \\
\hline & \multicolumn{5}{|l|}{$\square$ Não Identificado. } \\
\hline & $\begin{array}{l}\text { 12. Validação: } \\
\text { (Confiabilidade da Informacão) }\end{array}$ & $\square \mathrm{Ba}$ & & $\square$ Média & $\square$ Elevada. \\
\hline & \multicolumn{5}{|l|}{ 13. Sinopse } \\
\hline & \multicolumn{5}{|c|}{ 14. Características/Curiosidades } \\
\hline & \multicolumn{5}{|l|}{ 15. Requisitos de interface } \\
\hline & \multicolumn{3}{|l|}{ Navegação fácil } & $\square \operatorname{Sim}$ & $\square$ Não \\
\hline & \multicolumn{3}{|l|}{ Cores amenas } & $\square \operatorname{Sim}$ & $\square$ Não \\
\hline & \multicolumn{3}{|l|}{ Contraste de cores } & $\square \operatorname{Sim}$ & $\square$ Não \\
\hline & \multicolumn{3}{|c|}{ Fácil leitura } & $\square \operatorname{Sim}$ & $\square$ Não \\
\hline & \multicolumn{3}{|c|}{$\begin{array}{l}\text { Possibilidade de interação } \\
\text { (E-mail, Chat, Blog etc.) }\end{array}$} & $\square \operatorname{Sim}$ & $\square$ Não \\
\hline & \multicolumn{5}{|l|}{ Identidade visual } \\
\hline & \multicolumn{3}{|c|}{ Logomarca, banners } & $\square \operatorname{Sim}$ & $\square$ Não \\
\hline & \multicolumn{3}{|c|}{ Animações, multimídia } & $\square \operatorname{Sim}$ & $\square$ Não \\
\hline & \multicolumn{3}{|c|}{ Presença de Notícias, Informações } & $\square \operatorname{Sim}$ & $\square$ Não \\
\hline & 16. Aplicação/Possibilida & de de u & lização docente & $\square \operatorname{Sim}$ & $\square$ Não \\
\hline
\end{tabular}




\section{NOTAS}

${ }^{1}$ As manifestações da cibercultura abrangem várias subculturas, desde videogames, webart, música, fotografia, filmes, universo hacker, tecnologias de ponta, poesia digital e ciberjornalismo, passando pelas comunidades virtuais e práticas sociais online, tais como chats, weblogs, fotologs, webcams, listas, newsgroups ou fóruns. Abrange também o cibersexo, o imaginário cyberpunk e até as FlashMobs, as manifestações-relâmpago, combinadas e divulgadas no ciberespaço por pessoas, a maioria desconhecidas, para se reunirem em locais públicos e dispersarem-se logo em seguida sem uma causa definida. De um modo geral fala-se de ciberarte, ciberliteratura, ciberciência, cibercidadania, cibersociologia, ciberpsicologia, cibergeografia e cibersociedades, e até a criação de cidades digitais também é considerada um subproduto desta nova expressão cultural.

${ }^{2}$ Um estudo introdutório sobre essas questões pode ser encontrado em: PALACIOS, Marcos. A internet como ambiente de pesquisa: problemas de validação e normalização de documentos online. Revista da FAEEBA, Faculdade de Educação do Estado da Bahia, Salvador, n.6, jul.-dez. 1996.

${ }^{3}$ SCHOLAR.GOOGLE. Disponível em: scholar.google.com.br/intl/pt-BR/scholar/about. html; Acesso em: 2 jun. 2006.

${ }^{4}$ SANTAELLA, Lucia. Culturas e artes do pós-humano: da cultura das mídias à cibercultura. São Paulo: Paulus, 2003. p.20.

${ }^{5}$ ASSMANN, H. Redes digitais e metamorfose do aprender. Petrópolis (RJ): Vozes, 2005. p.9.

${ }^{6}$ Um texto de fácil acesso, que apresenta a lógica de funcionamento do Google, foi publicado pela revista SuperInteressante (n.201, jun. 2004), intitulado: "O Mundo Google". Também já é possível encontrar nas livrarias mais de uma dezena de títulos de obras que abordam diferentes aspectos dessa ferramenta de busca. O próprio website do mecanismo de busca disponibiliza algumas informações básicas sobre seu funcionamento e dicas de operacionalização: www.google.com.br/intl/pt-BR/about.html.

${ }^{7}$ A revista SuperInteressante (jun. 2004) comparou o funcionamento do Google ao do mundo acadêmico, onde a importância de uma publicação é aferida pelo número de citações que ela recebe em outras obras do meio universitário.

${ }^{8}$ GOOGLE. Disponível em: www.google.com.br/intl/pt_BR//why_use.html; Acesso em: 4 jun. 2006.

${ }^{9}$ GALIMBERTI, Carlo; GATTI, Fabiana. Nova mídia e família. In: PELUSO, Ângelo (Org.) Informática e afetividade. Bauru (SP): Edusc, 1998.

${ }^{10}$ TURKLE, Sherry. A vida no ecrã: a identidade na era da internet. Lisboa: Relógio D’água, 1997.

${ }^{11}$ RHEINGOLD, Howard. The virtual community. Disponível em: www.rheingold.com/ vc/book/; Acesso em: 4 jun. 2006. 
${ }^{12}$ CASTELLS, Manuel. A galáxia da internet: reflexões sobre a internet, os negócios e a sociedade. Rio de Janeiro: Jorge Zahar, 2003. p.108.

${ }^{13}$ WELLMAN, Barry; GULIA, Milena. Comunidades virtuais como comunidades: os surfistas da rede não viajam sozinhos. Disponível em: members.fortunecity.com/cibercultura/ vol6/comucomo.html; Acesso em: 5 mar. 2005.

${ }^{14}$ LÉVY, Pierre. A inteligência coletiva: por uma antropologia do ciberespaço. 3.ed. São Paulo: Loyola, 2000.

${ }^{15}$ www.amsterdam.nl/asp/get.asp? ItmIdt=00000494\&SitIdt $=00000005 \&$ VarIdt=00000002.

${ }^{16}$ www.comune.bologna.it/.

${ }^{17}$ www.aveiro-digital.pt/.

${ }^{18}$ ZANCHETI, 2004, citado em DA SILVA, Michele Tancman Candido. A (ciber)geografia das cidades digitais. Scripta Nova. Revista Electrónica de Geografia y Ciências Sociales, Barcelona: Universidad de Barcelona, v.VIII, n.170 (36), 1 ago. 2004. [ISSN:1138-9788]. Disponível em: www.ub.es/geocrit/sn/sn-170-36.htm; Acesso em: 30 nov. 2004.

${ }^{19}$ www.redegoverno.gov.br/.

${ }^{20}$ ANTONIO, Jorge Luiz. O gênero poesia digital. Symposium, ano 5, n.1, jan.-jun. 2001. p.65.

${ }^{21}$ www.ekac.org./index.html.

${ }^{22}$ www.capparelli.com.br.

${ }^{23}$ www.pucsp.br/pos/cos/epe/mostra/; www.ociocriativo.com.br/poesiadigital/epoesia/; artecno.ucs.br/; www.cce.ufsc.br/nupill/; www.lucialeao.pro.br/.

${ }^{24}$ www.aulablog.com/.

${ }^{25}$ LÉVY, Pierre. Cibercultura. São Paulo: Ed. 34, 1999. p.27.

${ }^{26}$ LÉVY, Pierre. As tecnologias da inteligência: o futuro do pensamento na era da informática. Trad. Carlos Irineu da Costa. São Paulo: Ed. 34, 1993. p.10-11.

Artigo recebido em 20 de janeiro de 2012. Aprovado em 10 de abril de 2012. 